\title{
Differential role of residual metabolic tumor volume in inoperable stage III NSCLC after chemoradiotherapy \pm immune checkpoint inhibition
}

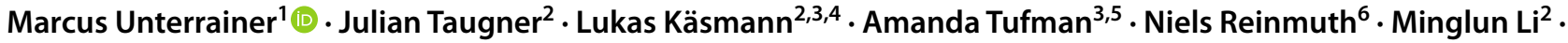 \\ Lena M. Mittlmeier ${ }^{7}$. Peter Bartenstein ${ }^{7}$ • Wolfgang G. Kunz ${ }^{1}$. Jens Ricke ${ }^{1}$ - Claus Belka ${ }^{2,3,4} \cdot$ Chukwuka Eze $^{2}$. \\ Farkhad Manapov ${ }^{2,3,4}$
}

Received: 29 July 2021 / Accepted: 9 October 2021 / Published online: 19 October 2021

(c) The Author(s) 2021

\begin{abstract}
Background The PET-derived metabolic tumor volume (MTV) is an independent prognosticator in non-small cell lung cancer (NSCLC) patients. We analyzed the prognostic value of residual MTV (rMTV) after completion of chemoradiotherapy (CRT) in inoperable stage III NSCLC patients with and without immune checkpoint inhibition (ICI).

Methods Fifty-six inoperable stage III NSCLC patients (16 female, median 65.0 years) underwent ${ }^{18}$ F-FDG PET/ CT after completion of standard CRT. rMTV was delineated on ${ }^{18} \mathrm{~F}$-FDG PET/CT using a standard threshold (liver $\mathrm{SUV}_{\text {mean }}+2 \times$ standard deviation). 21/56 patients underwent additional ICI (CRT-IO, 21/56 patients) thereafter. Patients were divided in volumetric subgroups using median split dichotomization (MTV $\leq 4.3 \mathrm{ml}$ vs. $>4.3 \mathrm{ml}$ ). rMTV, clinical features, and ICI-application were correlated with clinical outcome parameters (progression-free survival (PFS), local PFS (LPFS), and overall survival (OS).

Results Overall, median follow-up was 52.0 months. Smaller rMTV was associated with longer median PFS (29.3 vs. 10.5 months, $p=0.015)$, LPFS (49.9 vs. 13.5 months, $p=0.001)$, and OS (63.0 vs. 23.0 months, $p=0.003)$. CRT-IO patients compared to CRT patients showed significantly longer median PFS (29.3 vs. 11.2 months, $p=0.034$ ), LPFS (median not reached vs. 14.0 months, $p=0.016$ ), and OS (median not reached vs. 25.2 months, $p=0.007$ ). In the CRT subgroup, smaller rMTV was associated with longer median PFS (33.5 vs. 8.6 months, $p=0.001)$, LPFS (49.9 vs. 10.1 months, $p=0.001$ ), and OS (63.0 vs. 16.3 months, $p=0.004)$. In the CRT-IO subgroup, neither PFS, LPFS, nor OS were associated with MTV $(p>0.05$ each). The findings were confirmed in subsequent multivariate analyses.

Conclusion In stage III NSCLC, smaller rMTV is highly associated with superior clinical outcome, especially in patients undergoing CRT without ICI. Patients with CRT-IO show significantly improved outcome compared to CRT patients. Of note, clinical outcome in CRT-IO patients is independent of residual MTV. Hence, even patients with large rMTV might profit from ICI despite extensive tumor load.
\end{abstract}

Keywords NSCLC $\cdot$ Immunotherapy $\cdot$ Metabolic tumor volume $\cdot$ Durvalumab $\cdot$ Nivolumab

This article is part of the Topical Collection on Oncology - Chest

Marcus Unterrainer

marcus.unterrainer@med.uni-muenchen.de

1 Department of Radiology, University Hospital, LMU Munich, Marchioninistr. 15, 81377 Munich, Germany

2 Department of Radiotherapy and Radiation Oncology, University Hospital, LMU Munich, Munich, Germany

3 Member of the German Center for Lung Research (DZL), Comprehensive Pneumology Center Munich (CPC-M), Munich, Germany
4 German Cancer Consortium (DKTK), Partner Site Munich, Munich, Germany

5 Department of Internal Medicine V, LMU Munich, Munich, Germany

6 Asklepios Lung Clinic, Munich-Gauting, Germany

7 Department of Nuclear Medicine, University Hospital, LMU Munich, Munich, Germany 


\section{Introduction}

Advanced stage III non-small cell lung cancer (NSCLC) represents a heterogenous tumor entity regarding patient and tumor features [1-5] leading to interdisciplinary treatment strategies and regimens in these mostly inoperable patient cohort [6-10]. So far, standard treatment in stage III NSCLC consisted of a combination of platinum-based chemotherapy applied concurrently or sequentially to thoracic irradiation (CRT) leading to improved clinical outcome in terms of local control, metastasis free, and overall survival compared to irradiation alone [11]. Beyond this combined approach, immune checkpoint inhibition (ICI) has evolved as additional treatment option NSCLC patients [12], especially with regard to the first US Food and Drug Administration (FDA) approval for PD-1 inhibition (nivolumab) in 2015 in advanced or metastatic NSCLC [13, 14]. Consequently, further combined treatment regimens with PD-L1 inhibition (pembrolizumab) in the KEYNOTE-189 and 407 trials showed improved clinical outcome in NSCLC patients independent of the PD-L1 status compared to mere standard chemotherapy $[15,16]$. Recent ground-breaking clinical data were presented in the PACIFIC trial suggesting a continuous PD-L1 inhibition (Durvalumab) after the completion of standard CRT due to distinctly improved patient outcome considering PD-L1 inhibition after standard CRT as new standard of care [8]. Moreover, additional data suggest more combinatory possibilities to reach long lasting tumor control $[12,17]$.

PET imaging has gained lasting clinical importance in the therapeutic workup of NSCLC patients [18, 19], e. g., for radiotherapy planning [20], whole body staging [21], or treatment monitoring [22]. Interestingly, the PETderived metabolic tumor volume (MTV) has evolved as tool for response assessment and prognostication [23, 24]. An association of the residual MTV (rMTV) after completion of CRT with the further disease course has been described, e. g., indicating a cut-off of $25.0 \mathrm{ml} \mathrm{rMTV}$ as prognosticator for clinical outcome [25, 26]; moreover, additional data suggested further rMTV cut-offs such as $1.0 \mathrm{ml} \mathrm{rMTV} \mathrm{[25].}$

Therefore, we aimed at assessing the prognostic value of the PET-derived rMTV in stage III NSCLC patients after completion of standard CRT with regard to consecutive ICI consolidation (CRT-IO) in direct comparison to stage III NSCLC patients undergoing standard CRT only, to assess whether prognostic stratification using rMTV on PET is also valid for CRT-IO treatment regimens in the light of ICI and changing standards of care.

\section{Methods}

\section{Patients}

Fifty-six patients with histologically proven, inoperable, and locally advanced NSCLC stage IIIA-C (UICC 7th edition) and ${ }^{18} \mathrm{~F}$-FDG PET/CT imaging after completion of combined RCT with or without immune checkpoint inhibitor therapy consolidation from clinical routine 2011-2018 were included (during analyses, patients were reclassified according to the 2018 UICC 8th edition). All patients were treated at a single tertiary cancer center. Prior to treatment, basic patient characteristics were assessed. Cranial contrast-enhanced magnetic resonance imaging (MRI) or contrast-enhanced head computed tomography scan (CT) was performed in all cases. All patients received routine blood work to assess kidney function as well as complete blood count and underwent pulmonary function testing. Patients receiving durvalumab maintenance were given durvalumab intravenously at a dose of $10 \mathrm{mg} / \mathrm{kg}$ every 2 weeks up to 12 months ( 24 cycles), until progression or unacceptable toxicity according to the Common Toxicity Criteria for Adverse Events (CTCAE) version 5. Patients receiving nivolumab were treated in the NICOLAS trial [27].

All patients were discussed prior to treatment at the multidisciplinary tumor board, and all patients were deemed inoperable by an experienced group of thoracic surgeons, pulmonologists, and radiation oncologists. Patients with an initial performance status ECOG $>1$ and poor lung function (DLCO $<40 \%$, FEV $1<11$ or on longterm oxygen therapy) were excluded from this analysis.

\section{Image acquisition and data evaluation}

All PET/CT scans were performed at the same institution using a GE Discovery 690 PET/CT scanner (GE Healthcare, Chicago, IL, USA). Scans were initiated 60-90 min after intravenous administration of $20 \mathrm{mg}$ furosemide, 10-20 mg butylscopolamine, and ${ }^{18}$ F-FDG, when no medical contraindication was given. PET/CT examinations were performed in the treatment position (patient's arms overhead, wingstep) on carbon fiber couch. PET/ CT imaging was performed including a diagnostic, contrast-enhanced CT scan in portal-venous phase $(350 \mathrm{mg}$ of Imeron at $1.5 \mathrm{ml} / \mathrm{kg}$ body weight). PET was acquired with $2.5 \mathrm{~min}$ per bed position. Images were reconstructed iteratively using TrueX (three iterations, 21 subsets) with Gaussian post-reconstruction smoothing $(2 \mathrm{~mm}$ full width at half-maximum). For MTV delineation, a background activity of the liver (mean $\mathrm{SUV}_{\text {liver }}$ ) was derived using a 
$3.0 \mathrm{~cm}$ spherical volume of interest (VOI) including the respective standard deviation (SD) within this VOI. The respective cut-off for MTV delineation was set as mean $\mathrm{SUV}_{\text {liver }}+2 \times \mathrm{SD}_{\text {liver }}$ [28]. Moreover, the maximal SUV $\left(\mathrm{SUV}_{\max }\right)$ of the tumor manifestations was derived. The SUV measurements were performed using automated software in a 3D volume tool (Hybrid Viewer 3D, Hermes Medical Solutions, Stockholm, Sweden).

\section{Clinical parameters}

Beyond the PET-derived MTV, further clinical parameters were assessed including age, sex, histological subtypes, UICC stage (IIIA-C), planning target volume (PTV), reached radiation dose at radiotherapy (RT), application of RCT-IO, and application of previous induction chemotherapy.

\section{Outcome parameters/tumor progression}

Clinical and image-derived parameters were correlated with the patients' progression-free survival (PFS) as defined by RECIST 1.1 [29-31], local PFS (LPFS), and overall survival (OS) to derive associations of clinical and image-derived parameters with the direct clinical outcome.

\section{Statistics}

IBM® SPSS $®$ Statistics (version 25, IBM Corp., Armonk, NY, USA). Normal distribution was assessed using the Shapiro-Wilk test. Descriptive statistics are displayed as mean + SD or median (range). Kaplan-Meier curves were used for PFS, LPFS, and OS calculation and log-rank test for univariate comparison of PFS, LPFS, and OS regarding ordinary variables; PFS, LPFS, and OS are displayed as median survival with $95 \%$ confidence interval (CI). For testing of continuous parameters, a dichotomization was performed either using previously published cut-offs or using median split. Significant parameters from univariate analysis were consecutively included into the multivariate analysis, where results are displayed as hazard ratio (HR) and CI. Correlation analysis was performed using Pearson correlation coefficient. Statistical significance was defined as two-tailed $p$-values $<0.05$.

\section{Results}

\section{Patients/clinical features}

Overall, 56 stage III NSCLC patients with a median age of 65 (range, 33-83) years were included (40/56 males (71.4\%), 16/56 females (28.6\%)). Of those, 9/56 (16.1\%) comprised stage IIIA, 27/56 (48.2\%) stage IIIB, and
20/56 (35.7\%) stage IIIC with an underlying histology of adenocarcinoma in $11 / 56(19.7 \%)$ cases, squamous cell carcinoma in $41 / 56(73.2 \%)$, and other entities in $4 / 56$ (7.1\%) cases. During CRT, a radiation dose of at least 60 Gray was reached by $47 / 56(83.9 \%)$ and a dose $<60$ Gray in $9 / 56(16.1 \%)$ patients. 30/56 (53.6\%) patients consecutively comprised a planning target volume prior to irradiation of at least $700 \mathrm{ml}[32,33]$ and 26/56 (46.4\%) with a PTV $<700 \mathrm{ml}$. After completion of CRT, 35/56 $(62.5 \%)$ patients underwent clinical follow-up (historical data), and 21/56 (37.5\%) additionally underwent ICI consolidation being sequential therapy with durvalumab in $12 / 21(57.1 \%)$ cases and concurrent/sequential ICI with nivolumab in 9/21 cases (42.9\%) (please see Table 1).

Table 1 Patient characteristics

\begin{tabular}{|c|c|}
\hline \multicolumn{2}{|l|}{ Age } \\
\hline Median (range) & $65(33-83)$ yrs \\
\hline \multicolumn{2}{|l|}{ Sex } \\
\hline Male & $40(71.4 \%)$ \\
\hline Female & $16(28.6 \%)$ \\
\hline \multicolumn{2}{|l|}{ Histology } \\
\hline Adenocarcinoma & $11(19.7 \%)$ \\
\hline Squamous cell carcinoma & $41(73.2 \%)$ \\
\hline Others & $4(7.1 \%)$ \\
\hline \multicolumn{2}{|l|}{ Stage } \\
\hline IIIA & $9(16.1 \%)$ \\
\hline IIIB & $27(48.2 \%)$ \\
\hline IIIC & $20(35.7 \%)$ \\
\hline \multicolumn{2}{|l|}{ Therapy } \\
\hline CRT-IO & $21(37.5 \%)$ \\
\hline CRT & $35(62.5 \%)$ \\
\hline \multicolumn{2}{|l|}{ Mode of IO } \\
\hline Durvalumab (sequential) & $12(57.1 \%)$ \\
\hline Nivolumab (concurrent/sequential) & $9(42.9 \%)$ \\
\hline \multicolumn{2}{|l|}{ Induction chemotherapy } \\
\hline Yes & $26(46.6 \%)$ \\
\hline No & $30(53.6 \%)$ \\
\hline \multicolumn{2}{|l|}{ Cumulative RT dose } \\
\hline$<60 \mathrm{~Gy}$ & $9(16.1 \%)$ \\
\hline$\geq 60 \mathrm{~Gy}$ & $47(83.9 \%)$ \\
\hline \multicolumn{2}{|l|}{ Residual MTV } \\
\hline Median (range) & $4.3(0.0-144.0) \mathrm{ml}$ \\
\hline \multicolumn{2}{|l|}{$S U V_{\max }$} \\
\hline Median (range) & $13.8(2.0-43.0)$ \\
\hline \multicolumn{2}{|l|}{ PTV } \\
\hline$<700 \mathrm{ml}$ & $30(53.6 \%)$ \\
\hline$\geq 700 \mathrm{ml}$ & $26(46.4 \%)$ \\
\hline
\end{tabular}




\section{rMTV and SUV max $_{\text {on }}{ }^{18}$ F-FDG PET/CT}

All patients received ${ }^{18} \mathrm{~F}$-FDG PET/CT after completion of CRT for rMTV assessment (12 \pm 6 weeks, median 10 weeks). Here, a median rMTV of $4.3(0.0-144.0) \mathrm{ml}$ was observed. No residual activity (i.e., rMTV of $0.0 \mathrm{ml}$ ) was present in 18/56 $(32.1 \%$ ) patients, a rMTV $\leq 1.0 \mathrm{ml}$ in $23 / 56(41.1 \%)$ patients, and a rMTV $\leq 25.0 \mathrm{ml}$ in $41 / 56$ patients $(73.2 \%)$. Overall, there was a median $\mathrm{SUV}_{\text {max }}$ of 13.8 (range, 2.0-43.0) (see also Table 1).

\section{Progression-free survival}

Overall, there was a median follow-up time of 52.0 months, and median PFS was 14.2 months. Patients with RCT-IO compared to RCT showed a significantly longer median PFS (29.3 vs. 11.2 months, $p=0.034$ ). Also, patients with smaller rMTV (by median split dichotomization using a cut-off of $4.3 \mathrm{ml}$ ) comprised a significantly longer PFS than those with larger rMTV (16.3 vs. 11.2 months, $p=0.015$ ). Also, $\mathrm{SUV}_{\max }$ showed a significant association with PFS (29.3 vs. 12.7 months, $p=0.049$ ). All other parameters showed no association with PFS $(p>0.05)$. On multivariate analysis, both omission of CRT-ICI (HR 2.6, $p=0.009$ ) and larger rMTV $>4.3 \mathrm{ml}$ kept statistical significance (HR 2.4, p=0.009), whereas $\mathrm{SUV}_{\max }$ showed no association with PFS on multivariate analysis. All other parameters were not included in the multivariate analysis, respectively (please see Table 2).

\section{Local progression-free survival}

In the whole cohort, there was a median LPFS of 20.4 months. Again, patients with RCT-IO compared to RCT showed a significantly longer median LPFS (median not reached vs. 14.0 months, $p=0.004$ ). Analogously,
Table 2 Uni-/multivariate analysis PFS (median overall: 14.2 (11.9-16.5) months)

\begin{tabular}{|c|c|c|c|c|}
\hline \multirow[b]{2}{*}{ Parameter } & \multicolumn{2}{|l|}{ Univariate analysis } & \multicolumn{2}{|l|}{ Multivariate analysis } \\
\hline & Median PFS (95\% CI) & Significance & Hazard ratio $(95 \% \mathrm{CI})$ & Significance \\
\hline \multicolumn{5}{|l|}{ Age } \\
\hline$<65$ years & $15.4(11.1-19.7)$ & $\mathrm{p}=0.615$ & - & - \\
\hline$\geq 65$ years & $14.6(10.5-18.7)$ & & & \\
\hline \multicolumn{5}{|l|}{ Sex } \\
\hline Male & $15.3(11.5-19.1)$ & $p=0.691$ & - & - \\
\hline Female & $14.2(7.1-21.3)$ & & & \\
\hline \multicolumn{5}{|l|}{ Histology } \\
\hline Adeno & $15.4(7.1-23.7)$ & $p=0.747$ & - & - \\
\hline Squamous/other & $15.3(11.0-19.6)$ & & & \\
\hline \multicolumn{5}{|l|}{ Stage } \\
\hline IIIA & $12.7(5.7-19.7)$ & $p=0.195$ & - & - \\
\hline IIIB & $19.7(5.6-33.8)$ & & & \\
\hline IIIC & $11.2(6.9-15.5)$ & & & \\
\hline \multicolumn{5}{|l|}{ Therapy } \\
\hline CRT-IO & $29.3(10.4-48.2)$ & $p=0.034$ & $2.6(1.3-5.4)$ & $p=0.009$ \\
\hline CRT & $11.2(6.1-16.3)$ & & & \\
\hline \multicolumn{5}{|c|}{ Induction chemotherapy } \\
\hline Yes & $15.4(13.4-17.4)$ & $p=0.877$ & - & - \\
\hline No & $12.9(1.3-24.6)$ & & & \\
\hline \multicolumn{5}{|l|}{ Cum. RT dose } \\
\hline$<60$ Gy & $8.7(8.4-8.9)$ & $p=0.172$ & - & - \\
\hline$\geq 60 \mathrm{~Gy}$ & $16.2(12.7-19.7)$ & & & \\
\hline \multicolumn{5}{|c|}{ Residual MTV MS } \\
\hline$<4.3 \mathrm{ml}$ & $29.3(8.5-50.1)$ & $p=0.015$ & $2.4(1.2-4.7)$ & $p=0.009$ \\
\hline$\geq 4.3 \mathrm{ml}$ & $10.5(6.7-14.3)$ & & & \\
\hline \multicolumn{5}{|l|}{$\mathbf{S U V}$ max } \\
\hline$<13.8$ & $29.3(8.7-49.9)$ & $p=0.049$ & $1.8(0.9-3.5)$ & $p=0.143$ \\
\hline$\geq 13.8$ & $12.7(9.0-16.3)$ & & & \\
\hline \multicolumn{5}{|l|}{ PTV } \\
\hline$<700 \mathrm{ml}$ & $16.3(13.5-19.1)$ & $p=0.505$ & - & - \\
\hline$\geq 700 \mathrm{ml}$ & $11.2(8.2-14.2)$ & & & \\
\hline
\end{tabular}


patients with smaller rMTV (cut-off of $4.3 \mathrm{ml}$ ) showed a significantly longer PFS than those with larger rMTV (49.9 vs. 13.5 months, $p=0.001$ ). A larger PTV was also accompanied by a significantly shorter LPFS (34.7 vs. 2.8 months, $p=0.017$ ). All other parameters showed no association with clinical outcome in terms of LPFS $(p>0.05)$. On multivariate analysis, both omission of CRT-ICI (HR 3.5, $\mathrm{p}=0.004$ ) and larger $\mathrm{rMTV}>4.3 \mathrm{ml}$ kept statistical significance (HR 4.2, p <0.001), whereas PTV showed no significance on multivariate analysis. All other parameters were not included in the multivariate analysis, respectively (please see Table 3 ).

\section{Overall survival}

In the whole cohort, the median OS was 52.0 months. CRT-IO was associated with significantly longer
OS compared to CRT only (median not reached vs. 25.2 months, $p=0.007$ ). Again, rMTV (cut-off $4.3 \mathrm{ml}$ ) was associated with significantly longer OS in patients with smaller rMTV (63.0 vs. 23.0 months, $p=0.003$ ). A lower $\mathrm{SUV}_{\max }$ was also associated with OS (63.0 vs. $24.9, p=0.016)$. PTV also showed significant association with OS, as patients with smaller initial PTV also showed a significantly longer median OS compared to those with larger PTV at CRT initiation (63.0 vs. 23.0, $p=0.017)$. Absolute values of PTV and BTV were not correlated with each other $(r=0.219, p=0.105)$, so that direct inter-correlation effects on multivariate analysis can be excluded. On multivariate analysis, an association with OS was found in the following parameters: CRT HR 3.5, $p=0.023$; rMTV HR 3.9, $p=0.002$; and PTV HR 2.6, $p=0.026$. All other parameters were not associated with OS on univariate analyses including
Table 3 Uni-/multivariate analysis LPFS (median overall: 20.4 (3.5-37.3) months)

\begin{tabular}{|c|c|c|c|c|}
\hline \multirow[b]{2}{*}{ Parameter } & \multicolumn{2}{|l|}{ Univariate analysis } & \multicolumn{2}{|l|}{ Multivariate analysis } \\
\hline & Median IPFS (95\% CI) & Significance & Hazard ratio $(95 \% \mathrm{CI})$ & Significance \\
\hline \multicolumn{5}{|l|}{ Age } \\
\hline$<65$ years & $20.4(12.0-28.8)$ & $p=0.750$ & - & - \\
\hline$\geq 65$ years & $15.3(0.0-43.9)$ & & & \\
\hline \multicolumn{5}{|l|}{ Sex } \\
\hline Male & $20.4(8.1-32.7)$ & $p=0.934$ & - & - \\
\hline Female & $16.9(0.0-40.9)$ & & & \\
\hline \multicolumn{5}{|l|}{ Histology } \\
\hline Adeno & $16.3(6.4-26.2)$ & $p=0.212$ & - & - \\
\hline Squamous/other & $23.6(3.4-43.8)$ & & & \\
\hline \multicolumn{5}{|l|}{ Stage } \\
\hline IIIA & $15.3(7.7-22.8)$ & $p=0.156$ & - & - \\
\hline IIIB & $34.7(18.4-48.6)$ & & & \\
\hline IIIC & $14.3(9.4-19.1)$ & & & \\
\hline \multicolumn{5}{|l|}{ Therapy } \\
\hline CRT-IO & Not reached & $p=0.004$ & $3.5(1.5-8.3)$ & $p=0.004$ \\
\hline CRT & $14.0(9.3-18.7)$ & & & \\
\hline \multicolumn{5}{|c|}{ Induction chemotherapy } \\
\hline Yes & $16.9(7.4-26.4)$ & $p=0.779$ & - & - \\
\hline No & $23.6(0-47.3)$ & & & \\
\hline \multicolumn{5}{|l|}{ Cum. RT dose } \\
\hline$<60$ Gy & $10.5(5.3-15.6)$ & $p=0.059$ & - & - \\
\hline$\geq 60 \mathrm{~Gy}$ & $33.8(15.1-51.9)$ & & & \\
\hline \multicolumn{5}{|c|}{ Residual MTV MS } \\
\hline$<4.3 \mathrm{ml}$ & $49.9(5.3-94.5)$ & $p=0.001$ & $4.2(1.9-9.0)$ & $p<0.001$ \\
\hline$\geq 4.3 \mathrm{ml}$ & $13.5(7.7-19.3)$ & & & \\
\hline \multicolumn{5}{|l|}{$S U V_{\max }$} \\
\hline$<13.8$ & $34.7(6.3-62.9)$ & $p=0.165$ & - & - \\
\hline$\geq 13.8$ & $15.3(6.9-23.6)$ & & & \\
\hline \multicolumn{5}{|l|}{ PTV } \\
\hline$<700 \mathrm{ml}$ & $34.7(19.5-49.8)$ & $p=0.017$ & $1.9(0.9-4.0)$ & $p=0.060$ \\
\hline$\geq 700 \mathrm{ml}$ & $12.8(9.4-16.3)$ & & & \\
\hline
\end{tabular}


Table 4 Uni-/multivariate analysis OS (median overall: 52.0 (14.1-89.8) months)

\begin{tabular}{|c|c|c|c|c|}
\hline \multirow[b]{2}{*}{ Parameter } & \multicolumn{2}{|l|}{ Univariate analysis } & \multicolumn{2}{|l|}{ Multivariate analysis } \\
\hline & Median IPFS (95\% CI) & Significance & Hazard ratio $(95 \% \mathrm{CI})$ & Significance \\
\hline \multicolumn{5}{|l|}{ Age } \\
\hline$<65$ years & $63.0(14.2-112)$ & $p=0.828$ & - & - \\
\hline$\geq 65$ years & $31.8(5.9-57.6)$ & & & \\
\hline \multicolumn{5}{|l|}{ Sex } \\
\hline Male & $31.8(12.0-51.6)$ & $p=0.623$ & - & - \\
\hline Female & $52.0(9.7-94.2)$ & & & \\
\hline \multicolumn{5}{|l|}{ Histology } \\
\hline Adeno & $28.8(20.4-37.2)$ & $p=0.317$ & - & - \\
\hline Squamous/other & $52.0(21.5-82.5)$ & & & \\
\hline \multicolumn{5}{|l|}{ Stage } \\
\hline IIIA & $23.6(22.0-25.2)$ & $p=0.079$ & - & - \\
\hline IIIB & $77.5(11.4-143)$ & & & \\
\hline IIIC & $52.0(0-108)$ & & & \\
\hline \multicolumn{5}{|l|}{ Therapy } \\
\hline CRT-IO & Not reached & $p=0.007$ & $3.5(1.2-10.6)$ & $p=0.023$ \\
\hline CRT & $25.2(11.5-38.9)$ & & & \\
\hline \multicolumn{5}{|c|}{ Induction chemotherapy } \\
\hline Yes & $52.0(13.3-90.6)$ & $p=0.803$ & - & - \\
\hline No & $31.7(14.1-89.8)$ & & & \\
\hline \multicolumn{5}{|l|}{ Cum. RT dose } \\
\hline$<60 \mathrm{~Gy}$ & $23.0(5.9-40.2)$ & $p=0.095$ & - & - \\
\hline$\geq 60 \mathrm{~Gy}$ & $52.0(19.1-84.8)$ & & & \\
\hline \multicolumn{5}{|c|}{ Residual MTV MS } \\
\hline$<4.3 \mathrm{ml}$ & $63.0(42.9-83.2)$ & $p=0.003$ & $3.9(1.6-9.1)$ & $p=0.002$ \\
\hline$\geq 4.3 \mathrm{ml}$ & $23.0(12.5-33.4)$ & & & \\
\hline \multicolumn{5}{|l|}{$S U V_{\max }$} \\
\hline$<13.8$ & $63.0(41.3-84.7)$ & $p=0.016$ & $2.3(0.9-5.6)$ & $p=0.067$ \\
\hline$\geq 13.8$ & $24.9(17.7-32.2)$ & & & \\
\hline \multicolumn{5}{|l|}{ PTV } \\
\hline$<700 \mathrm{ml}$ & $63.0(18.7-107)$ & $p=0.017$ & $2.6(1.2-6.1)$ & $p=0.026$ \\
\hline$\geq 700 \mathrm{ml}$ & $23.0(15.7-30.4)$ & & & \\
\hline
\end{tabular}

$\mathrm{SUV}_{\max }(p>0.05$ each $)$; consecutively, these factors were not included in multivariate analyses (please see Table 4).
To account for different, previously published cut-off values for rMTV (i.e., $1.0 \mathrm{ml}$ and $25.0 \mathrm{ml} \mathrm{rMTV}$ ), these values were also analyzed using univariate analysis comprising

Table 5 Uni-/multivariate analysis for further residual MTV cut-off values

\begin{tabular}{llllll} 
Median PFS (95\% CI) & $\begin{array}{l}\text { Hazard ratio } \\
\text { PFS (95\% CI) }\end{array}$ & Median LPFS (95\% CI) & $\begin{array}{l}\text { Hazard ratio } \\
\text { LPFS (95\% CI) }\end{array}$ & Median OS (95\% CI) & $\begin{array}{l}\text { Hazard ratio } \\
\text { OS (95\% CI) }\end{array}$ \\
\hline & & & & & \\
$29.3(2.1-56.5)$ & - & $49.9(4.3-95.5)$ & 3.4 & $63.0(43.0-83.1)$ & 3.1 \\
$13.5(8.2-18.7)$ & & $15.3(11.4-19.1)$ & $(1.5-7.7)$ & $28.8(19.9-37.7)$ & $(1.3-7.6)$ \\
$p=0.105$ & - & $p=0.015$ & $p=0.003$ & $p=0.023$ & $p=0.013$ \\
& & & & & 5.0 \\
$19.7(8.9-30.5)$ & 3.3 & $49.9(10.2-89.6)$ & 4.2 & $63.0(23.7-102)$ & $(2.1-12.1)$ \\
$10.7(6.2-15.2)$ & $(1.6-6.9)$ & $13.5(7.5-19.5)$ & $(1.9-9.1)$ & $19.2(11.2-27.2)$ & $p<0.001$ \\
$p=0.020$ & $p=0.001$ & $p=0.004$ & $p<0.001$ & $p=0.009$ & \\
\hline
\end{tabular}


analogous results compared to the currently chose median split approach (please see Table 5).

\section{Subgroup analyses-influence of rMTV in CRT/ CRT-IO patients}

In the overall group, significant influence of both the extent of rMTV and the application of CRT-IO in stage III NSCLC patients were described. Therefore, subgroups of patients receiving with CRT or CRT-IO were analyzed with regard to influence of rMTV on clinical outcome.

In the subgroup of patients receiving CRT only, the rMTV cut-off of $4.3 \mathrm{ml}$ remained in strong association with PFS (median 33.5 vs. 8.6 months, $p=0.001$ ). Also, smaller rMTV was associated with longer LPFS (median 49.9 vs. 10.1 months, $p=0.001)$ and $\mathrm{OS}$ (63.0 vs. 16.3 months, $p=0.001$ ).

In contrast to the overall and CRT cohorts, no association of rMTV and clinical outcome was observed in the CRT-IO group; here, PFS (median 29.3 vs. 19.7, $p=0.909$ ), LPFS (median not reached vs. 33.5 months, $p=0.291$ ), and OS (median not reached in both groups, $p=0.720$ ) were comparable between patients with small and larger rMTV (please see Table 6; for a patient example, please see Fig. 1).

\section{Discussion}

The present study was designed to investigate a prognostic role of rMTV in inoperable stage III NSCLC patients treated with CRT and CRT-IO. All patients had completed primary multimodal treatment as well as post-treatment ${ }^{18} \mathrm{~F}-\mathrm{FDG}$ $\mathrm{PET} / \mathrm{CT}$ in the same institution.

In the overall outcome analysis, we found that a smaller rMTV after therapy completion and the subsequent application of ICI maintenance treatment were strongly associated with favorable outcome with significant hazards in the multivariate analyses. This was the case for PFS, locoregional control (i.e., LPFS), and OS. Of note, the size of the PTV was also a prognosticator for OS with contribution in the multivariate analysis without significant inter-correlation with rMTV. Other clinical parameter (e.g., TNM-stage) or image-derived parameters (e.g., $\mathrm{SUV}_{\max }$ ) were not relevant as prognosticators in the present study.

Despite the association of CRT-IO and rMTV with favorable clinical outcome, we could demonstrate in the subsequent subgroup analyses that the extent of rMTV has a diverging role with special regard to the application of ICI maintenance therapy; in the subgroup of patients without ICI (i.e., CRT only), the extent of the rMTV was drastically associated with the clinical outcome. Vice versa, in the subgroup of CRT-IO patients, the rMTV was not associated with the clinical outcome (PFS, LRPFS, and OS) during the follow-up period.

Generally, rMTV was confirmed to be associated with patient survival. All tested rMTV values $(1,4$, and $25 \mathrm{ml})$ have shown a correlation with LRPFS, PFS, and OS in the whole studied cohort. However, the principal finding was a different prognostic influence of rMTV in patients treated with and without ICI. Present results suggest that rMTV may have significantly lower impact on the locoregional tumor control as well as survival in patients treated with CRT-IO.

The role of initial and residual MTV and MTV changes after conventional CRT were previously described. Our group has shown that pre- and post-treatment MTV as well as at least $80 \%$ of their reduction after completion of CRT were significantly associated with overall survival $[25,26]$. Both studies from Ohri et al. have also shown a significant correlation between pre-treatment total MTV and survival in locally advanced NSCLC after CRT. Additionally, a significant impact of "lesion_MTV" on the post-treatment local control was reported [34, 35]. Earlier, Machtay et al. in the cooperative
Table 6 Residual MTV vs. $\mathrm{CRT} \pm \mathrm{IO}$

\begin{tabular}{llll}
\hline $\begin{array}{l}\text { Outcome parameter/ } \\
\text { residual MTV }\end{array}$ & Overall median $(95 \%$ CI $)$ & CRT-IO median $(95 \%$ CI) & CRT median (95\% CI) \\
\hline PFS & & & \\
$<4.3 \mathrm{ml}$ & $29.3(8.5-50.1)$ & $29.3(9.9-48.7)$ & $33.5(4.7-62.3)$ \\
$\geq 4.3 \mathrm{ml}$ & $10.5(6.7-14.3)$ & $19.7($ n.a. $)$ & $8.6(7.6-9.6)$ \\
Significance & $p=0.015$ & $p=0.909$ & $p=0.001$ \\
LPFS & & & \\
$<4.3 \mathrm{ml}$ & $49.9(5.3-94.5)$ & Not reached & $49.9(0.0-106.3)$ \\
$\geq 4.3 \mathrm{ml}$ & $13.5(7.7-9.3)$ & $33.5(8.7-58.3)$ & $10.1(7.6-12.5)$ \\
Significance & $p=0.001$ & $p=0.291$ & $p=0.001$ \\
OS & & & \\
$<4.3 \mathrm{ml}$ & $63.0(42.9-83.2)$ & Not reached & $63.0(42.2-83.8)$ \\
$\geq 4.3 \mathrm{ml}$ & $23.0(12.5-33.4)$ & Not reached & $16.3(9.7-22.8)$ \\
Significance & $p=0.003$ & $p=0.720$ & $p=0.001$ \\
\hline
\end{tabular}

n.a. not available. 


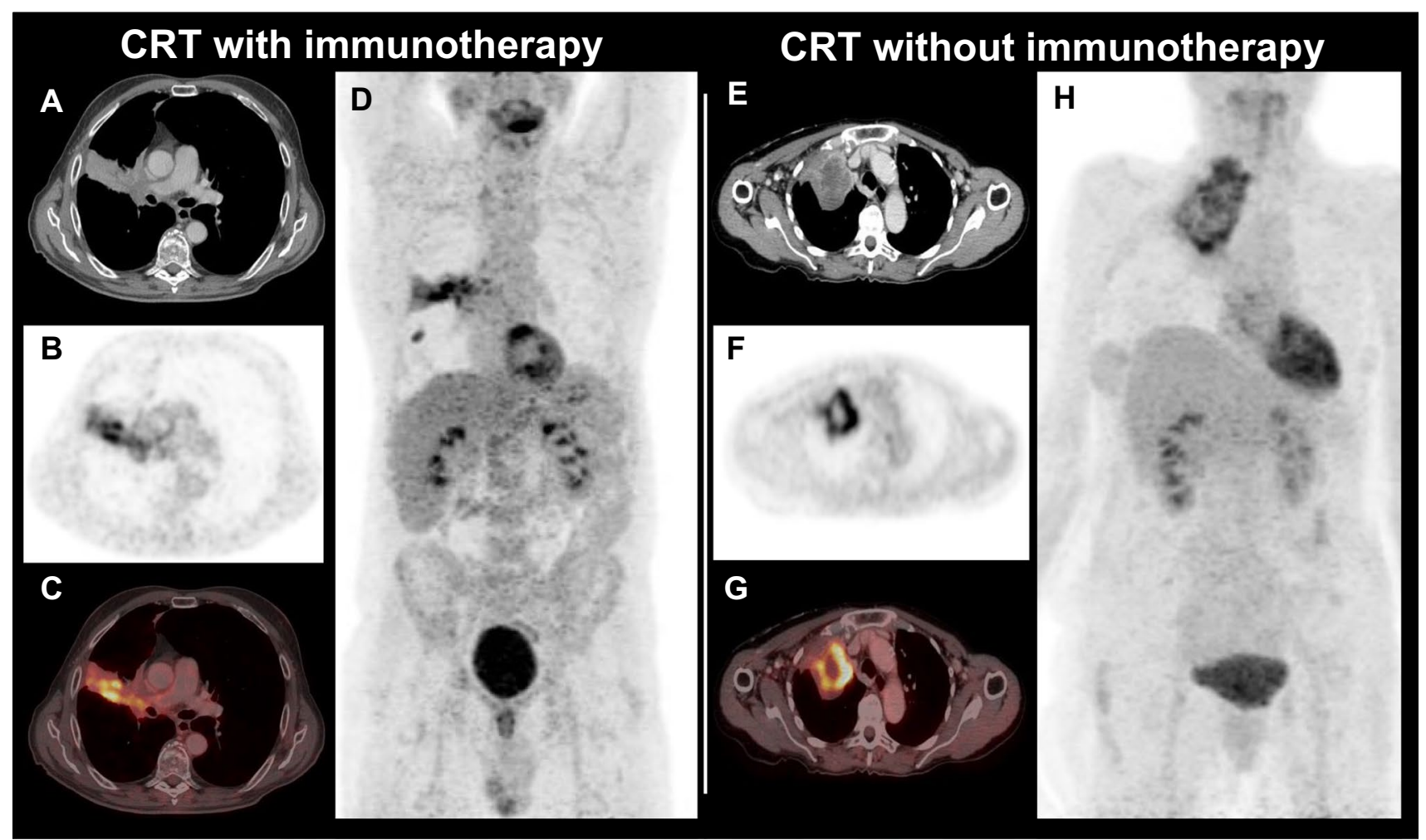

Fig. 1 Left: NSCLC patient with CRT-IO and rMTV of $124.0 \mathrm{ml}$, but OS of at least 43.6 months (still during follow-up). Right: NSCLC patients with CRT only and rMTV of $116.0 \mathrm{ml}$, but comparably low

ACRIN6668/RTOG0235 trial have revealed that a higher posttreatment tumor SUV is also associated with worse survival in locally advanced NSCLC after CRT [36].

Concerning CRT-IO as a new tri-modal treatment approach for inoperable stage III NSCLC, the data on PET/ $\mathrm{CT}$ and metabolic parameters are very sparse. In the groundbreaking PACIFIC trial, an initial ${ }^{18} \mathrm{~F}-\mathrm{FDG}$-PET/CT was not obligatory because of a multi-national real-life study design and different general eligibility of the hybrid imaging. In addition, a blinded central-review radiological evaluation in the follow-up including duration of response was based on the conventional CT diagnostic (RECIST). Ohri et al. have recently published an exploratory retrospective single-center analysis evaluating an implementation of durvalumab maintenance after CRT. A survival benefit from durvalumab was found to be independent from initial MTV [37].

Ongoing translational and biomarker studies on CRT-IO will address a prognostic role of pre-and post-treatment ${ }^{18} \mathrm{~F}$-FDG$\mathrm{PET} / \mathrm{CT}$ in lung cancer patients receiving CRT-IO. In the ESR 1814205 CRT-IO feasibility study in poor risk and/or elderly patients with stage III NSCLC, a ${ }^{18} \mathrm{~F}$-FDG PET/CT is obligatory within 30 days for enrollment (NCT04441138). A phase II translational and biomarker DART study of the Norwegian group has incorporated a serial ${ }^{18}$ F-FDG-PET/CT imaging together with
OS of 8.0 months. A/E, contrast-enhanced $\mathrm{CT}$; B/F, ${ }^{18} \mathrm{~F}$-FDG PET; $\mathrm{C} / \mathrm{G}$, fused $\mathrm{PET} / \mathrm{CT}$; D/H, maximum intensity projections (MIP)

collection of tumor tissue as well as blood, urine, and stool samples [38]. For the ICI as a monotherapy in advanced NSCLC, several studies have already reported about a potential of metabolic parameters to predict post-treatment progression $[39,40]$. A role of baseline MTV as a prognostic factor in metastatic NSCLC treated with nivolumab was described [41]. Additionally, a longitudinal ${ }^{18} \mathrm{~F}-\mathrm{FDG}$ PET/CT analysis was also shown to have a potential to differentiate immune-dissociated response during ICI treatment [19, 42].

Within the current literature, what is a clinical implementation of our findings? Our study suggests a role of the ICI maintenance treatment after CRT as a "stabilizer" of the local-regional and distant tumor control as well as consequently LPFS and OS. A significant improvement of local tumor control with durvalumab after CRT was recently reported [43, 44]. This "stabilization" effect of ICI after CRT has a major impact on the significant improvement of patient survival in inoperable stage III NSCLC. Of note, in the light with current literature, we observed a significant association of the rMTV with clinical outcome in the CRT patients; however, this effect was no longer present in patients with subsequent ICI (i.e., CRT-IO group). This emphasizes the phenomenon that patients with large rMTV after CRT completion may build a special high-risk subgroup that significantly profit 
from ICI maintenance therapy despite extensive rMTV on PET-imaging, as no clinical outcome parameter in the CRTIO group was associated with the extent of rMTV on PET - a drastic difference to patients without ICI.

Hence, the immunological interpretation of the rMTV after CRT is a phenomenon that must be addressed in future studies. A re-biopsy of the metabolic active region after CRT may be necessary to clarify the background of this phenomenon, and future biomarker studies need to consider this invasive procedure. Complementary, a serial investigation of circulating tumor DNA as a marker of molecular residual disease and longitudinal peripheral immunophenotyping may give information concerning interactions between local and systemic anti-tumor immune response. According to limitations of present study, a retrospective design and relatively low patient number must be mentioned. However, completion of all diagnostic and treatment procedures within a same tertiary cancer center as well as a comprehensive statistical analysis supports the present results.

\section{Conclusion}

Overall, ICI maintenance treatment and rMTV are significantly associated with clinical outcome in inoperable stage III NSCLC after CRT. Despite its strong prognostic role in CRT alone patients, the extent of rMTV in the CRT-IO subgroup is not associated with outcome; hence, even patients with extensive rMTV after CRT completion significantly profit from ICI maintenance treatment.

Funding Open Access funding enabled and organized by Projekt DEAL.

\section{Declarations}

Ethics approval The study was authorized by the local ethics committee in accordance with the ICH Guideline for Good Clinical Practice (GCP) and the declaration of Helsinki.

Informed consent All patients gave written consent to undergo PET/ CT scans as part of the clinical routine. Written informed consent for retrospective data analysis was waived by the local ethics committee.

\section{Conflict of interest The authors declare no competing interests.}

Open Access This article is licensed under a Creative Commons Attribution 4.0 International License, which permits use, sharing, adaptation, distribution and reproduction in any medium or format, as long as you give appropriate credit to the original author(s) and the source, provide a link to the Creative Commons licence, and indicate if changes were made. The images or other third party material in this article are included in the article's Creative Commons licence, unless indicated otherwise in a credit line to the material. If material is not included in the article's Creative Commons licence and your intended use is not permitted by statutory regulation or exceeds the permitted use, you will need to obtain permission directly from the copyright holder. To view a copy of this licence, visit http://creativecommons.org/licenses/by/4.0/.

\section{References}

1. Choi HS, Jeong BK, Jeong H, Lee YH, Ha IB, Song JH, et al. Application of the new 8th TNM staging system for non-small cell lung cancer: treated with curative concurrent chemoradiotherapy. Radiat Oncol. 2017;12:1-8.

2. Ettinger DS, Aisner DL, Wood DE, Akerley W, Bauman J, Chang JY, et al. NCCN guidelines insights: non-small cell lung cancer, version 5.2018. J Natl Comprehen Cancer Network. 2018;16:807-21.

3. Käsmann L, Niyazi M, Blanck O, Baues C, Baumann R, Dobiasch $\mathrm{S}$, et al. Predictive and prognostic value of tumor volume and its changes during radical radiotherapy of stage III non-small cell lung cancer. Strahlenther Onkol. 2018;194:79-90.

4. Postmus P, Kerr K, Oudkerk M, Senan S, Waller D, Vansteenkiste $\mathrm{J}$, et al. Early and locally advanced non-small-cell lung cancer (NSCLC): ESMO clinical practice guidelines for diagnosis, treatment and follow-up. Annal Oncol. 2017;28:iv1-21.

5. Taugner J, Käsmann L, EzeC, Dantes M, Roengvoraphoj O, Gennen K, et al. Survival score to characterize prognosis in inoperable stage III NSCLC after chemoradiotherapy. Translat Lung Cancer Res. 2019;8:593.

6. Abdel-Rahman O. Outcomes of surgery as part of the management of metastatic non-small-cell lung cancer: a surveillance, epidemiology and end results database analysis. Cancer Invest. 2018;36:238-45.

7. Walraven I, Damhuis R, Ten Berge M, Rosskamp M, Van Eycken L, De Ruysscher D, et al. Treatment variation of sequential versus concurrent chemoradiotherapy in stage III non-small cell lung cancer patients in the Netherlands and Belgium. Clin Oncol. 2017;29:e177-85.

8. Antonia SJ, Villegas A, Daniel D, Vicente D, Murakami S, Hui R, et al. Overall survival with durvalumab after chemoradiotherapy in stage III NSCLC. N Engl J Med. 2018;379:2342-50.

9. Käsmann L, Eze C, Dantes M, Roengvoraphoj O, Niyazi M, Belka $\mathrm{C}$, et al. State of clinical research of radiotherapy/chemoradiotherapy and immune checkpoint inhibitor therapy combinations in solid tumours-a German radiation oncology survey. Eur J Cancer. 2019;108:50-4.

10. Käsmann L, Taugner J, Manapov F. Chemo-/immuno-/radiotherapy combination in treatment of solid cancer. Oncotarget. 2019;10:5387.

11. O'Rourke N, i Figuls MR, Bernadó NF, Macbeth F (2010) Concurrent chemoradiotherapy in non-small cell lung cancer. Cochrane Database Syst Rev

12. Käsmann L, Eze C, Taugner J, Roengvoraphoj O, Dantes M, Schmidt-Hegemann N-S, et al. Chemoradioimmunotherapy of inoperable stage III non-small cell lung cancer: immunological rationale and current clinical trials establishing a novel multimodal strategy. Radiat Oncol. 2020;15:1-14.

13. Borghaei H, Paz-Ares L, Horn L, Spigel DR, Steins M, Ready NE, et al. Nivolumab versus docetaxel in advanced nonsquamous non-small-cell lung cancer. N Engl J Med. 2015;373:1627-39.

14. Brahmer J, Reckamp KL, Baas P, Crinò L, Eberhardt WE, Poddubskaya $\mathrm{E}$, et al. Nivolumab versus docetaxel in advanced squamouscell non-small-cell lung cancer. N Engl J Med. 2015;373:123-35.

15. Gandhi L, Rodríguez-Abreu D, Gadgeel S, Esteban E, Felip E, De Angelis F, et al. Pembrolizumab plus chemotherapy in metastatic non-small-cell lung cancer. N Engl J Med. 2018;378:2078-92.

16. Paz-Ares L, Luft A, Vicente D, Tafreshi A, Gümüş M, Mazières $\mathrm{J}$, et al. Pembrolizumab plus chemotherapy for squamous nonsmall-cell lung cancer. N Engl J Med. 2018;379:2040-51.

17. Foster CC, Sher DJ, Rusthoven CG, Verma V, Spiotto MT, Weichselbaum RR, et al. Overall survival according to immunotherapy 
and radiation treatment for metastatic non-small-cell lung cancer: a National Cancer Database analysis. Radiat Oncol. 2019;14:1-13.

18. Unterrainer M, Eze C, Ilhan $\mathrm{H}$, Marschner S, Roengvoraphoj O, Schmidt-Hegemann N-S, et al. Recent advances of PET imaging in clinical radiation oncology. Radiat Oncol. 2020;15:1-15.

19. Eze C, Schmidt-Hegemann N-S, Sawicki LM, Kirchner J, Roengvoraphoj O, Käsmann L, et al. PET/CT imaging for evaluation of multimodal treatment efficacy and toxicity in advanced NSCLC current state and future directions. Euro J Nuclear Med Molecul Imag. 2021;48:3975-89.

20. Nestle U, Schimek-Jasch T, Kremp S, Schaefer-Schuler A, Mix M, Küsters A, et al. Imaging-based target volume reduction in chemoradiotherapy for locally advanced non-small-cell lung cancer (PET-Plan): a multicentre, open-label, randomised, controlled trial. Lancet Oncol. 2020;21:581-92.

21. Lardinois D, Weder W, Hany TF, Kamel EM, Korom S, Seifert B, et al. Staging of non-small-cell lung cancer with integrated positron-emission tomography and computed tomography. N Engl J Med. 2003;348:2500-7.

22. Cremonesi M, Gilardi L, Ferrari ME, Piperno G, Travaini LL, Timmerman R, et al. Role of interim 18 F-FDG-PET/CT for the early prediction of clinical outcomes of non-small cell lung cancer (NSCLC) during radiotherapy or chemo-radiotherapy. A systematic review. Euro J Nuclear Med Molec Imag. 2017;44:1915-27.

23. Seban R-D, Mezquita L, Berenbaum A, Dercle L, Botticella A, Le Pechoux C, et al. Baseline metabolic tumor burden on FDG PET/ CT scans predicts outcome in advanced NSCLC patients treated with immune checkpoint inhibitors. Eur J Nucl Med Mol Imag. 2020;47:1147-57. https://doi.org/10.1007/s00259-019-04615-x.

24. Chin AL, Kumar KA, Guo HH, Maxim PG, Wakelee H, Neal JW, et al. Prognostic value of pretreatment FDG-PET parameters in high-dose image-guided radiotherapy for oligometastatic nonsmall-cell lung cancer. Clin Lung Cancer. 2018;19:e581-8.

25. Roengvoraphoj O, Eze C, Wijaya C, Dantes M, Taugner J, Tufman A, et al. How much primary tumor metabolic volume reduction is required to improve outcome in stage III NSCLC after chemoradiotherapy? A single-centre experience. Eur J Nucl Med Mol Imag. 2018;45:2103-9.

26. Roengvoraphoj O, Wijaya C, Eze C, Li M, Dantes M, Taugner J, et al. Analysis of primary tumor metabolic volume during chemoradiotherapy in locally advanced non-small cell lung cancer. Strahlenther Onkol. 2018;194:107-15. https://doi.org/10.1007/ s00066-017-1229-3.

27. Peters S, Felip E, Dafni U, Belka C, Guckenberger M, Irigoyen A, et al. Safety evaluation of nivolumab added concurrently to radiotherapy in a standard first line chemo-radiotherapy regimen in stage III non-small cell lung cancer-the ETOP NICOLAS trial. Lung Cancer. 2019;133:83-7.

28. Im H-J, Bradshaw T, Solaiyappan M, Cho SY. Current methods to define metabolic tumor volume in positron emission tomography: which one is better? Nucl Med Mol Imag. 2018;52:5-15.

29 Goebel J, Hoischen J, Gramsch C, Schemuth HP, Hoffmann A-C, Umutlu L, et al. Tumor response assessment: comparison between unstructured free text reporting in routine clinical workflow and computer-aided evaluation based on RECIST 1.1 criteria. J Cancer Res Clin Oncol. 2017;143:2527-33.

30 Eisenhauer EA, Therasse P, Bogaerts J, Schwartz LH, Sargent D, Ford R, et al. New response evaluation criteria in solid tumours: revised RECIST guideline (version 1.1). Euro J Cancer. 2009;45:228-47.

31. Seitz AK, Rauscher I, Haller B, Krönke M, Luther S, Heck MM, et al. Preliminary results on response assessment using $68 \mathrm{Ga}-$ HBED-CC-PSMA PET/CT in patients with metastatic prostate cancer undergoing docetaxel chemotherapy. Eur J Nucl Med Mol Imag. 2018;45:602-12.
32. Karin M, Taugner J, Käsmann L, Eze C, Roengvoraphoj O, Tufman A, et al. Association of planning target volume with patient outcome in inoperable stage III NSCLC treated with chemoradiotherapy: a comprehensive single-center analysis. Cancers. 2020;12:3035.

33. Wiersma TG, Dahele M, Verbakel WF, van de Ven PM, de Haan PF, Smit EF, et al. Concurrent chemoradiotherapy for large-volume locally-advanced non-small cell lung cancer. Lung Cancer. 2013;80:62-7.

34. Ohri N, Bodner WR, Halmos B, Cheng H, Perez-Soler R, Keller $\mathrm{SM}$, et al. 18F-fluorodeoxyglucose/positron emission tomography predicts patterns of failure after definitive chemoradiation therapy for locally advanced non-small cell lung cancer. Int J Rad Oncol Biol Phys. 2017;97:372-80.

35. Ohri N, Piperdi B, Garg MK, Bodner WR, Gucalp R, Perez-Soler $\mathrm{R}$, et al. Pre-treatment FDG-PET predicts the site of in-field progression following concurrent chemoradiotherapy for stage III non-small cell lung cancer. Lung Cancer. 2015;87:23-7.

36. Machtay M, Duan F, Siegel BA, Snyder BS, Gorelick JJ, Reddin JS, et al. Prediction of survival by [18F] fluorodeoxyglucose positron emission tomography in patients with locally advanced non-small-cell lung cancer undergoing definitive chemoradiation therapy: results of the ACRIN 6668/RTOG 0235 trial. J Clin Oncol. 2013;31:3823.

37. Ohri N, Halmos B, Bodner WR, Cheng H, Garg MK, Gucalp $\mathrm{R}$, et al. Who benefits the most from adjuvant durvalumab after chemoradiotherapy for non-small cell lung cancer? An exploratory analysis Practical Radiation Oncology. 2021;11:e172-9.

38 Haakensen V, Horndalsveen H, Nymoen H, Holgersson G, Land LH, Koivunen J, et al. P17. 02 durvalumab after chemoradiotherapy (DART) for NSCLC patients-a phase II translational and biomarker study. J Thoracic Oncol. 2021;16:S351-2.

39 Park S, Lee Y, Kim T-S, Kim S-k, Han J-Y. Response evaluation after immunotherapy in NSCLC: early response assessment using FDG PET/CT. Medicine. 2020;99:e23815.

40. Rossi G, Bauckneht M, Genova C, Rijavec E, Biello F, Mennella $\mathrm{S}$, et al. Comparison between 18F-FDG PET-based and CTbased criteria in non-small cell lung cancer Patients treated with nivolumab. J Nucl Med. 2020;61:990-8.

41. Chardin D, Paquet M, Schiappa R, Darcourt J, Bailleux C, Poudenx M, et al. Baseline metabolic tumor volume as a strong predictive and prognostic biomarker in patients with non-small cell lung cancer treated with PD1 inhibitors: a prospective study. J Immunother Cancer. 2020;8:645.

42. Humbert O, Cadour N, Paquet M, Schiappa R, Poudenx M, Chardin D, et al. 18 FDG PET/CT in the early assessment of non-small cell lung cancer response to immunotherapy: frequency and clinical significance of atypical evolutive patterns. Eur J Nucl Med Mol Imaging. 2020;47:1158-67.

43. Abe T, Saito S, Iino M, Aoshika T, Ryuno Y, Ohta T, et al. Effect of durvalumab on local control after concurrent chemoradiotherapy for locally advanced non-small cell lung cancer in comparison with chemoradiotherapy alone. Thoracic cancer. 2021;12:245-50.

44. Taugner J, Käsmann L, Eze C, Tufman A, Reinmuth N, Duell T, et al. Durvalumab after chemoradiotherapy for PD-L1 expressing inoperable stage III NSCLC leads to significant improvement of local-regional control and overall survival in the real-world setting. Cancers. 2021;13:1613.

Publisher's note Springer Nature remains neutral with regard to jurisdictional claims in published maps and institutional affiliations. 